\title{
OPEN The impact of bacterial diversity on resistance to biocides in oilfields
}

\author{
Gabriela Feix Pereira ${ }^{1,2}$, Harry Luiz Pilz-Junior ${ }^{1}$ \& Gertrudes Corção ${ }^{1 凶}$
}

Extreme conditions and the availability of determinate substrates in oil fields promote the growth of a specific microbiome. Sulfate-reducing bacteria (SRB) and acid-producing bacteria (APB) are usually found in these places and can harm important processes due to increases in corrosion rates, biofouling and reservoir biosouring. Biocides such as glutaraldehyde, dibromo-nitrilopropionamide (DBNPA), tetrakis (hydroxymethyl) phosphonium sulfate (THPS) and alkyl dimethyl benzyl ammonium chloride (ADBAC) are commonly used in oil fields to mitigate uncontrolled microbial growth. The aim of this work was to evaluate the differences among microbiome compositions and their resistance to standard biocides in four different Brazilian produced water samples, two from a Southeast Brazil offshore oil field and two from different Northeast Brazil onshore oil fields. Microbiome evaluations were carried out through $16 \mathrm{~S}$ rRNA amplicon sequencing. To evaluate the biocidal resistance, the Minimum Inhibitory Concentration (MIC) of the standard biocides were analyzed using enriched consortia of SRB and APB from the produced water samples. The data showed important differences in terms of taxonomy but similar functional characterization, indicating the high diversity of the microbiomes. The APB and SRB consortia demonstrated varying resistance levels against the biocides. These results will help to customize biocidal treatments in oil fields.

In oil fields, systems containing water are prone to uncontrolled microbial growth, which may trigger serious problems. Uncontrolled microbial activity can increase oil contamination, microbially induced corrosion, biofouling and the generation of dangerous metabolic byproducts, such as hydrogen sulfide $\left(\mathrm{H}_{2} \mathrm{~S}\right)$, known as biosouring ${ }^{1,2}$.

In mature fields, the secondary recovery of oil requires water/gas injection to push the oil from the well to the platform surface. To decrease storage costs, produced water generated during oil extraction is commonly used, but it first receives a biocidal treatment to prevent microbial contamination in the well. Among the most employed biocides worldwide used in produced water treatment are glutaraldehyde (27\% of the market share), dibromo-nitrilopropionamide (DBNPA; $24 \%$ of the market share), tetrakis (hydroxymethyl) phosphonium sulfate (THPS; $9 \%$ of the market share) and alkyl dimethyl benzyl ammonium chloride (ADBAC; $3 \%$ of the market share) ${ }^{3}$. The Brazilian O\&G industry usually employs THPS (batch application) and/or ADBAC (continuous low dosage application) as chemical treatments for produced water ${ }^{4}$.

Due to the extreme environmental conditions found in oil fields, such as high temperature, low oxygen content and high salinity, some specific groups of bacteria are present. Among them, the main biocide targets are acid-producing bacteria (APB), also known as fermentative bacteria, and sulfate-reducing bacteria (SRB) ${ }^{5}$. APB produces several types of organic and inorganic acids and other metabolites under anaerobic conditions. The generated metabolites interact with steel surfaces, affecting electrochemical reactions and, consequently, the corrosion rate. The SRB group, in addition to increasing corrosion, is known to generate $\mathrm{H}_{2} \mathrm{~S}$, a toxic, corrosive and inflammable gas, which causes concerns in terms of oil field structural integrity and worker safety ${ }^{6}$.

The application of similar treatments over the years without technical monitoring selects those microorganisms with high biocide resistance levels ${ }^{7}$. Factors such as microbiome composition, treatment history and resistance level need to be observed to choose the best method for microbial control. Therefore, the aim of this study was to evaluate four different produced water samples in terms of their microbiome compositions and metabolic activities. The Minimum Inhibitory Concentration (MIC) of glutaraldehyde, DBNPA, THPS and ADBAC against $\mathrm{SRB}$ and $\mathrm{APB}$ consortia obtained from produced water samples were determined.

\footnotetext{
${ }^{1}$ Department of Microbiology, Immunology and Parasitology, Institute of Basic Health Sciences, Universidade Federal Do Rio Grande Do Sul, Rua Sarmento Leite 500, Porto Alegre, RS 90050-170, Brazil. ²Dorf Ketal Research and Development Center, Rua da Pedreira 559, Nova Santa Rita, RS 92480-000, Brazil. ${ }^{\varpi}$ email: corcao@ufrgs.br
} 


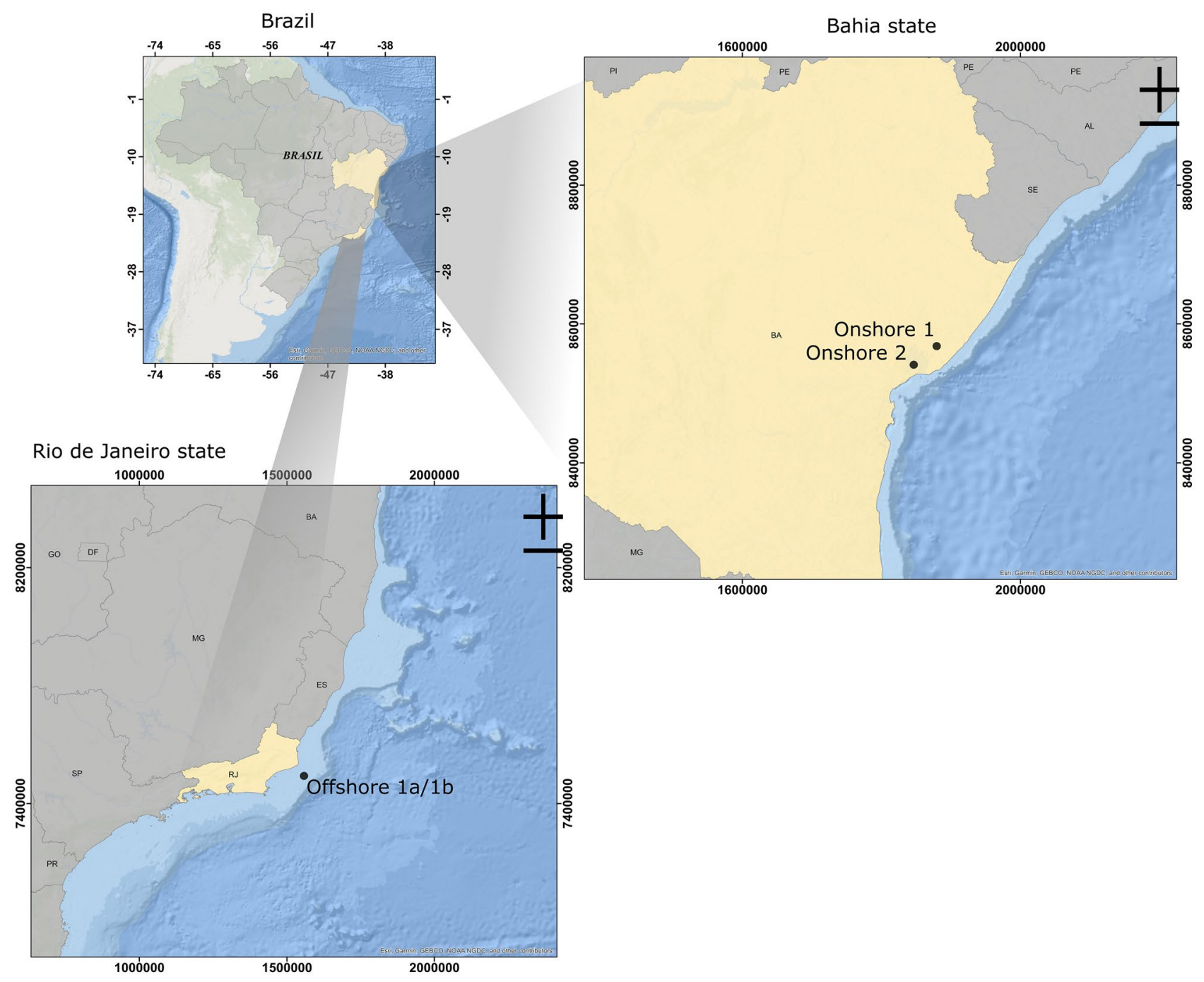

Figure 1. Map of Brazil with detailed locations of the sample collection points in Bahia State (right) and Rio de Janeiro State (botton). Created using the component ArcMap from the software ArcGIS 10.6.1 (https://www. $\operatorname{arcgis.com} /$ ).

\section{Materials and methods}

Produced water samples and biocides. Four samples of produced water from three Brazilian oil fields were used in this study. Two samples were collected in different wells from the same offshore field located in the state of Rio de Janeiro (Offshore 1a and Offshore 1b), and two samples were collected from different fields in the state of Bahia (Onshore 1 and Onshore 2) (Fig. 1). Sampling flasks were filled to the top to avoid oxygen contamination. The samples were kept refrigerated and in the dark during transportation and were filtered immediately after the arrived, within $72 \mathrm{~h}$ by a $0.22 \mu \mathrm{m}$ filter. The filters were maintained at $-20^{\circ} \mathrm{C}$ before analysis. Dorf Ketal Brazil Ltda. provided the produced water and biocide samples (glutaraldehyde, DBNPA, THPS and ADBAC).

Produced water characterization. Produced water samples were characterized immediately after receipt according to salinity, sulfate content, $\mathrm{pH}$ and microbial concentration. Salinity (chloride content) was determined by potentiometric titration in a Titrino Plus 848 (Metrohm, Switzerland). The equipment was connected to a silver electrode, and $0.01 \mathrm{~mol} \mathrm{~L}^{-1} \mathrm{AgNO}_{3}$ solution was used as the standard. Sulfate quantification in water samples was carried out by the ICP-OES Agilent 5100 technique (Agilent, USA). A sulfur standard was used to determine the sulfate content. $\mathrm{pH}$ was determined with a $\mathrm{pH}$ meter (Edge, Hanna Instruments). The microbial concentration was determined by ATP quantification using a luminometer (Photonmaster, Luminultra) and specific reagent kit (ATP Quench Gone Aqueous Kit, Luminultra).

DNA extraction and quality check. Two $100 \mathrm{~mL}$ aliquots of each sample were filtered through $0.45 \mu \mathrm{m}$ membranes to obtain duplicates. Total genomic DNA was extracted from each membrane using a DNEasy PowerSoil Kit (Qiagen, Germany) following the manufacturer's instructions. The extracted DNA was quantified by a Quantus fluorimeter (Promega, USA). 
16S rRNA gene amplification and sequencing. The V4 region of the 16S rRNA gene was amplified using primers 515F (5' GTGCCAGCMGCCGCGGTAA 3') and R806 (5' GGACTACHVGGGTWTCTAAT $3^{\prime}$ ), both modified to contain an Illumina adapter region ${ }^{8}$. PCR amplification was carried out by mixing $\sim 100 \mathrm{ng}$ of genomic DNA, $1.0 \mathrm{mM} \mathrm{MgCl}_{2}, 0.5 \mu \mathrm{M}$ of each primer, $0.2 \mathrm{mM}$ of dNTP, 2 U Platinum Taq DNA Polymerase High Fidelity (Life Technologies, USA), and $1 \times$ reaction buffer. The thermal cycling conditions for amplification were an initial denaturation $\left(2 \mathrm{~min}\right.$ at $\left.94{ }^{\circ} \mathrm{C}\right)$ followed by 25 cycles of amplification $\left(45 \mathrm{~s}\right.$ at $94{ }^{\circ} \mathrm{C}, 45 \mathrm{~s}$ at $55^{\circ} \mathrm{C}$ and $1 \mathrm{~min}$ at $72^{\circ} \mathrm{C}$ ) and a final extension cycle $\left(6 \mathrm{~min}\right.$ at $\left.72^{\circ} \mathrm{C}\right)$ in a Mastercycler Personal 5332 Thermocycler (Eppendorf, Germany).

Amplicons were purified using Agencourt AMPure XP beads (Beckman Coulter, USA) following the manufacturer's instructions. Sequencing was conducted on the Illumina MiSeq platform (Illumina Inc., USA) with a v2 $500 \mathrm{kit}$, which generates paired end reads of $250 \mathrm{bp}$.

Taxonomic profiling of bacterial communities. All the data were processed following standard bioinformatics pipelines, including quality control, sequence alignment (with chimera removal), taxonomic classification, operational taxonomic unit (OTU) clustering and community richness analysis (Mothur $1.44 .3^{9}$ ) using the SILVA database ${ }^{10}$ (release 138.1). Amplicon sequences are available at the European Bioinformatic Institute (EBI) under the EBI Metagenomic Database with accession number ERP121357.

Functional abundances were predicted through PICRUSt 2 software ${ }^{11}$ and annotated by KEGG ${ }^{12-15}$. The predicted functional abundances were scaled based on the abundance of taxa from which they were derived. Thus, high taxonomic abundances usually generate high functional abundances.

Composition of bacterial communities. Richness and bacterial abundance were examined in each sample for $\alpha$-diversity and $\beta$-diversity with multivariance analysis on a relative abundance matrix. Richness, bacterial abundance and microbiome composition were compared through Jaccard similarity based on observed richness using Tree.shared in Mothur?.

The $\alpha$-diversity was evaluated through the observed richness, Simpson's index and Shannon's index based on the number of OTUs. Diversity estimates were compared between fields by applying two-way ANOVA with a posterior Tukey test.

To verify the spatial distribution patterns of bacteria and their response to variables, multidimensional ordering was carried out to identify which explanatory variables could affect the variances between location and abundance. A canonical correspondence analysis (CCA) was performed to determine whether a linear or unimodal ordering method could be applied to the data. The highest gradient obtained was greater than 3.0 SD units, which indicated that a restricted method based on a unimodal model was adequate. For that, we used CCA (double scale) with an explanatory matrix (abiotic factors) with general averages for the following: $\mathrm{pH}$, chlorides and sulfates. The communities were tested and inferred by the possible ecological preferences for the explanatory variables, considering the different collection points. For a more conservative approach, it the analysis was carried out with the phyla and the main bacterial genera identified. Thus, a triple plot CCA was performed to better observe how explanatory variables (vectored lines) influence the distribution of samples and locations, represented in the axes. The type 2 scaling parameter was used to observe the position of the maximum values of the variables with the explanatory ones by the average of the orthogonal distance between samples and vectored lines. The analysis was conducted using the Vegan community ecology package in R version 2.5-7.

Culture media. Specific culture media were used for SRB and APB growth. For APB growth, Phenol Red Broth medium (Merck, Germany) with $15 \mathrm{~g} \mathrm{~L}^{-1}$ glucose was used. The medium was purged with $\mathrm{N}_{2}$ to decrease the oxygen content ${ }^{16}(1 \mathrm{~h}$ per L) and added to $30 \mathrm{~mL}$ sealed bottles. The bottles were sterilized in an autoclave for $15 \mathrm{~min}$ at $121^{\circ} \mathrm{C}$. The same process was carried out for the SRB growth medium, which was modified Postgate $\mathrm{E}^{17,18}\left(\mathrm{KH}_{2} \mathrm{PO}_{4}, 0.5 \mathrm{~g} \cdot \mathrm{L}^{-1} ; \mathrm{NH}_{4} \mathrm{Cl}, 1.0 \mathrm{~g} \cdot \mathrm{L}^{-1} ; \mathrm{Na}_{2} \mathrm{SO}_{4}, 1.0 \mathrm{~g} \cdot \mathrm{L}^{-1} ; \mathrm{CaCl}_{2} \cdot 6 \mathrm{H}_{2} \mathrm{O}, 1.0 \mathrm{~g} \cdot \mathrm{L}^{-1} ; \mathrm{MgCl}_{2} \cdot 7 \mathrm{H}_{2} \mathrm{O}, 1.8 \mathrm{~g} \cdot \mathrm{L}^{-1}\right.$; sodium lactate, $7.0 \mathrm{~mL} \cdot \mathrm{L}^{-1}$; yeast extract, $1.0 \mathrm{~g} \cdot \mathrm{L}^{-1}$; ascorbic acid, $0.1 \mathrm{~g} \cdot \mathrm{L}^{-1}$; $\mathrm{FeSO}_{4} \cdot 7 \mathrm{H}_{2} \mathrm{O}, 0.5 \mathrm{~g} \cdot \mathrm{L}^{-1}$; agar, $\left.1.0 \mathrm{~g} \cdot \mathrm{L}^{-1}\right)$. The $\mathrm{pH}$ was adjusted to 7.6 with $\mathrm{NaOH}$ solution, and before the use, $4.0 \mathrm{~mL} \cdot \mathrm{L}^{-1}$ of a $0.025 \%$ resazurin solution previously filtered in a $0.22 \mu \mathrm{m}$ membrane filter, was added.

Enrichment of SRB and APB from produced water samples. APB and SRB consortia were enriched in specific media for 21 days at $35^{\circ} \mathrm{C}$ (average oilfield temperature). APB and SRB consortia were transferred weekly $(10 \%(\mathrm{v} / \mathrm{v}))$ to sterile sealed bottles containing Phenol Red Glucose Broth and modified Postgate E, respectively. After inoculation with SRB or APB consortia, a layer of mineral oil was added to maintain the anaerobic environment.

Minimum inhibitory concentration (MIC) of biocides against SRB and APB. To evaluate the resistance of the consortia against glutaraldehyde, DBNPA, THPS and ADBAC, MIC analyzes were carried out. Concentrations of $25,50,100,250$ and $500 \mathrm{mg} \cdot \mathrm{L}^{-1}$ of the biocides were dosed in 96 -well microtiter plates ${ }^{19} \mathrm{con}^{-}$ taining specific culture medium and an inoculum of $1 \times 10^{6} \mathrm{cells} / \mathrm{mL}$, quantified by a luminometer (Photonmaster, Luminultra) using a specific reagent kit (ATP Quench Gone Aqueous Kit, Luminultra). A positive control of each consortium was used for the validation of the test. The bottles were incubated in an anaerobic jar with an anaerobiosis generator (Anaerobac, Probac, Brazil) for $72 \mathrm{~h}$ at $35^{\circ} \mathrm{C}$. 

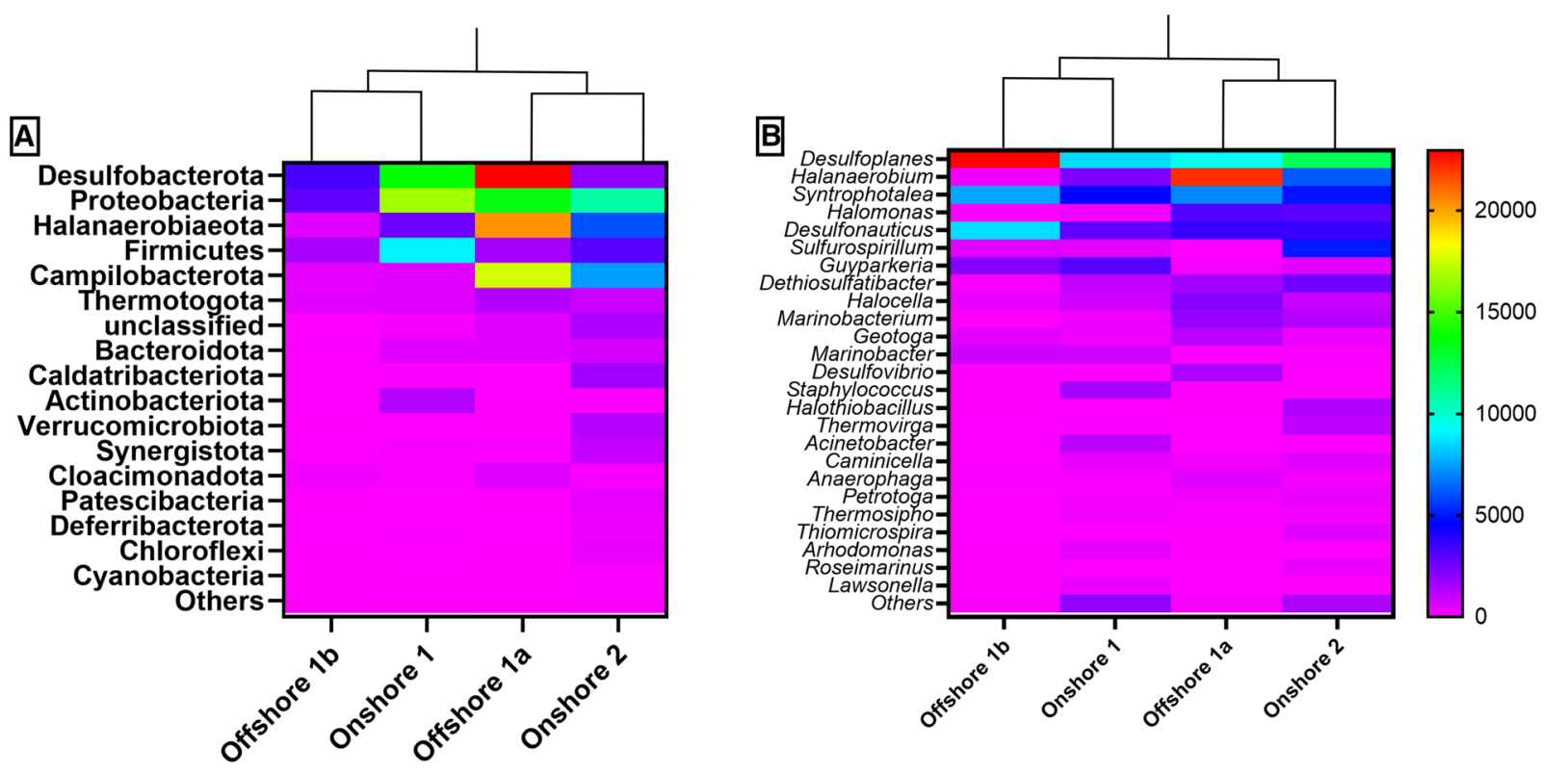

Figure 2. Heatmap of taxonomic analysis at the phylum level (A) and genus level (B).

\section{Results and discussion}

Produced water characterization. In the $O \& G$ industry, produced water is the term used for water emulsified with oil during the extraction process, and due to the large volumes generated, it is considered one of the most important effluents in O\&G. In 2009, the world generation of produced water was estimated to be $>70$ billion barrels per year. In Brazil, the average generation is approximately 224 million barrels per day ${ }^{20}$. Worldwide, the volume of produced water is increasing due to the maturation process of reservoirs and the greater number of production fields ${ }^{21,22}$.

Produced water presents a variable composition according to the geographic location of the field, age and depth of the well, composition of the oil, and extraction method ${ }^{21}$. Despite the proximity of the onshore fields where the samples were collected (Fig. 1), their chemical and biological characteristics were very distinct. Onshore 1, approximately $50 \mathrm{~km}$ from Onshore 2 , showed higher salinity and sulfate contents but lower $\mathrm{pH}$ and microorganism concentrations. The offshore samples presented more similar characteristics (except sulfate content), as expected, since they were collected from the same platform but different wells (Table S1-supplemental material).

Composition of the bacterial communities from produced water samples. The sequencing produced a total of 438,361 sequences from the produced water samples. After removal of primers, sequences not belonging to the hypervariable V4 region, preclusters and chimeras, 263,241 sequences were used for taxonomic identification. Using Mothur for removal, 258,741 bacterial sequences were filtered, of which 29,929 were unique sequences. A total of 2,636 OTUs were obtained, covering a maximum distance of $3 \%$ for the $16 \mathrm{~S}$ rRNA gene. The coverage was evaluated by a rarefraction curve (Figure S1A - supplemental material), where a trend in the reduction of the curve slope was observed, demonstrating that the majority of OTUs were sampled but sometimes not detected. Indications of alpha diversity showed significant differences $(\mathrm{p}<0.0001)$ between the collection sites. The Chao 1 index showed that most samples presented differences, except Offshore 1a and Onshore $1(p=0.8471)$. The Shannon index did not show significant differences between the samples $(p>0.9999)$ (Figure S1B-supplemental material). These data demonstrate that bacterial communities do not share rare species in an expressive way. OTUs from Archaea were found in low number (less than $0.1 \%$ ) in the samples.

Similar to the physical-chemical characteristics, the microbiome of produced water changed according to the sample collection location. However, some microorganisms with important ecological roles have been frequently reported. Sulfate- and sulfur-reducing, acid-producing, thermophilic, halotolerant and halophilic bacteria are the most common groups comprising oil reservoir ecosystems $s^{5,6}$. Phyla and genera belonging to these groups were also identified in the produced water samples evaluated in this study. Figure $2 \mathrm{~A}$ shows the relative abundance of bacterial phyla found in the samples. The results demonstrate the presence of Desulfobacterota, Proteobacteria, Halanaerobiaeota, Firmicutes and Campylobacterota as the most abundant phyla. The relative abundance of genera can be seen in Fig. 2B; Desulfoplanes (SRB), Halanaerobium (APB), Syntrophotalea (sulfur-reducing), Halomonas (APB), Desulfonauticus (SRB), Sulfurospirillum (sulfur-reducing) and Guyparkeria, also named Halothiobacillus (sulfur-oxidizing), were predominant. The identification of these groups of microorganisms can be explained by the extreme conditions found in oilfields, such as high sulfur derivative contents in water, high salinity and high temperatures.

Among the microorganisms found in the samples, SRB are generally the main target in biocidal treatments due to the negative impact caused by $\mathrm{H}_{2} \mathrm{~S}$ generation and increased corrosion rates ${ }^{23-25}$. Produced water normally provides favorable conditions for the development of SRB due to the concentrated supply of sulfate and low 
oxygen content ${ }^{26,27}$. All samples evaluated in this work demonstrated a high abundance of SRB. These microorganisms are able to use sulfate $\left(\mathrm{SO}_{4}{ }^{2-}\right)$ as an electron acceptor in dissimilatory sulfate reduction for anaerobic respiration processes, generating $\mathrm{H}_{2} \mathrm{~S}$ and other byproducts ${ }^{27,28}$.

In the analyzed samples, the sulfate content was highest in samples Onshore 1 and Offshore 1a (Table S1-supplemental material). Although sulfate plays an important role in the development of the SRB group, the sulfate content was not the only factor affecting the microbiome. Other factors, such as salinity, geographic location, and bacterial competition, influence the predominance of some genera over others.

Similar to SRB, sulfur-reducing bacteria generate $\mathrm{H}_{2} \mathrm{~S}$ but use only sulfur $\left(\mathrm{S}^{0}\right)$ and oxidized forms as electron acceptors (except sulfate). Bacteria from sulfur-reducing groups are able to grow through the dissimilatory reduction of elemental sulfur to sulfide in a respiratory type of metabolism ${ }^{29,30}$ and are frequently found in extreme environments, such as coal mine wastewater and heavy metal-containing waters ${ }^{31,32}$. Despite their similarities with the SRB group, sulfur-reducing bacteria show important differences in taxonomy ${ }^{33}$, suggesting that organic substrates suitable for SRB may not be suitable for their growth ${ }^{34}$. This group of microorganisms seems to have a key role in the balance of determinate microbiomes, but in most environments, especially in oilfield wastewaters, their role remains unclear.

APBs such as Halanaerobium and Halomonas intrinsically enter seawater due to their halophilic characteristics and are involved in corrosive processes ${ }^{35-38}$. Halanaerobium, predominant in Offshore 1a, is a strictly anaerobic and moderately halophilic genus that requires $\mathrm{NaCl}$ concentrations between 30,000 and $200,000 \mathrm{mg} \mathrm{L}^{-1}$ for optimal growth ${ }^{39}$. The role of APB microorganisms in biocorrosion has been demonstrated, mostly due to their capacity for biofilm formation ${ }^{38,40}$ and the production of acids from sugars ${ }^{6,41}$. In addition, studies have demonstrated the synergistic role of APB in SRB biofilms, where the presence of both groups enhances biofilm aggressiveness ${ }^{23,42}$. Another APB identified in the Offshore 1a sample was Geotoga. Despite the low relative abundance in this sample, Geotoga has been identified in oil reservoirs ${ }^{43,44}$ and fuel storange tanks ${ }^{45}$.

Another abundant genus found in the analyzed samples was Syntrophotalea, also named Pelobacter ${ }^{46,47}$. The Syntrophotalea genus consists of strictly anaerobic gram-negative bacteria whose members are unable to ferment sugars, metabolizing only an extremely limited number of substrates. This genus plays an important role in the fermentative degradation of unusual organic matter, such as ethanol and butanol, and is able to use sulfur $\left(S^{\circ}\right)$ as an electron acceptor in these reactions ${ }^{32}$. In addition, the association of Syntrophotalea species with methanogenic bacteria in the degradation of crude oil alkanes, an intrinsic substrate from oil reservoirs, was observed ${ }^{48,49}$.

A significant number of unclassified genera (38\% in the four samples), especially those collected from onshore fields, and the high number of OTUs demonstrated the high complexity of the microbiome in produced water. In addition to environmental factors, such as temperature, pressure and geographic location ${ }^{21}$, the microbiome complexity may be influenced by the water composition.

Figures 3 and 4 show CCA plots of phyla and genera, respectively, according to the abiotic factors associated with the produced water composition that may interfere with microbiome complexity $(\mathrm{pH}$, sulfate and chloride content). Samples Offshore $1 \mathrm{~b}$, Onshore 1 and Onshore 2 showed correlations with the factors $\mathrm{pH}$ and sulfate content. Desulfobacterota, the most representative SRB phylum found in the four samples, was influenced by these two factors. In addition, although much less abundant, some known APB phyla also demonstrated correlations with $\mathrm{pH}$ and sulfate content (Fermentibacterota, Acidobacteriota and Acetothermia). In terms of genera, $\mathrm{pH}$ was the most influential, and Desulfovibrio, Desulfoplanes and Desulfonauticus were influenced by this factor.

On the other hand, produced water is a complex matrix, where a small group of abiotic factors cannot reduce all other influences. In this case, factors not evaluated in this work may have contributed to the Onshore 1a microbial composition. Extreme conditions, such as pressure and temperature, and even the selective pressure caused by chemical agents applied in oil fields are examples of possible interfering abiotic factors.

Functional characterization of the microbiome from produced water. Through the taxonomic abundance of OTUs, the metabolic abundances were predicted. Despite a quite different microbiome taxonomy, the four samples showed remarkably similar metabolic activities (Fig. 5A).

As expected, primary metabolism, for maintenance of bacterial life, was the most abundant in all samples; however, biosynthesis of secondary metabolites also demonstrated substantial relative abundance. Secondary metabolites are produced for survival under certain conditions, such as microbial competition for nutrients or space and protection against abiotic stress ${ }^{50,51}$. Secondary metabolites, such as pantothenate, fatty acids, prodigiosin, biotin, cofactors and vitamins, inosine monophosphate, among others were predicted by KEGG according to microbial composition data.

Other important metabolic activities found were quorum sensing, biofilm formation, carbon, sulfur, nitrogen and methane metabolism, antimicrobial resistance and degradation of aromatic compounds. Quorum sensing and biofilm formation are related to population density control and response to stress and can also be associated with substrate limitation or other types of stress ${ }^{52,53}$. These metabolic activities have been described as a trigger for biofouling in oil fields, causing damage to membrane units, clogging pipes and harming systems and processes $^{54,55}$.

Carbon metabolism is essential for microbial growth due to its activity as an electron donor for respiration, and it is incorporated into cells as biomass. Usually, volatile fatty acids (VFAs) are the most common carbon sources in produced water, but hydrocarbons, including aromatic compounds, have also been found ${ }^{56}$. Initial hydrocarbon degradation presents high energy barriers to be overcome due to the apolar $\mathrm{C}-\mathrm{H}$ bond. Pelobacter, Desulfovibrio and other SRB are part of complex communities involved in anaerobic degradation of hydrocarbons under syntrophic conditions ${ }^{57}$.

Metabolism of sulfur and its derivatives has been frequently associated with negative impacts in oil fields and can increase biosouring in oil reservoirs (biosynthesis of $\left.\mathrm{H}_{2} \mathrm{~S}\right)^{55,56,58}$. The main mechanism for $\mathrm{H}_{2} \mathrm{~S}$ generation 


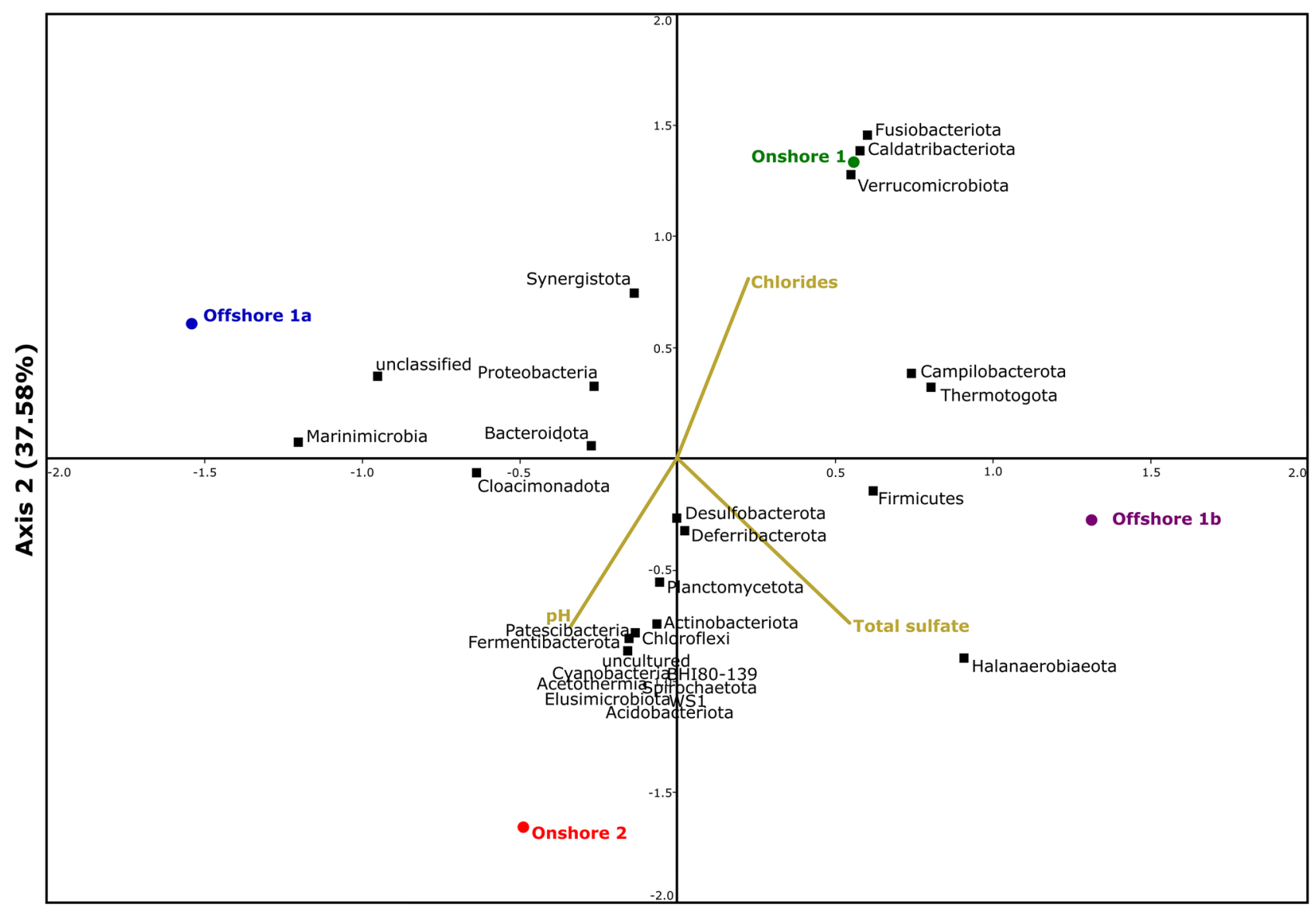

\section{Axis $1(62.42 \%)$}

Figure 3. Ordination tri plot of canonical correspondence analysis (CCA) between study sites and abiotic factors and phyla.

is the dissimilatory sulfate-reduction pathway, where sulfate is converted to sulfite and then to sulfide by an irreversible reaction. Additional studies suggest two possible alternative biosouring mechanisms: 1) thiosulfate reduction, when the medium presents a low sulfate content, or the presence of sulfate-reducing prokaryotes, and 2) sulfide generation through hydrogen and formate metabolization, mostly by the Desulfonauticus genus ${ }^{59}$.

Figure 5B shows the main metabolic pathways involved in sulfur metabolism in the produced water samples evaluated in this work. The highest relative abundances were observed for sulfate metabolism, sulfur amino acid synthesis and thiosulfate metabolism, as expected. However, dimethyl sulfoxide (DMSO) reduction seems to be an important method for anaerobic respiration in extremophiles ${ }^{60,61}$.

Despite the low sulfate concentration of Offshore $1 \mathrm{~b}$ (Table S1-supplemental material), the sample demonstrated the highest abundance of genes involved in sulfate metabolism. This result was derived from the high abundance of the genus Desulfoplanes in the sample (Fig. 3). Possibly, an unknown specific condition was promoting the growth of Desulfoplanes in Offshore $1 \mathrm{~b}$, for example, high concentrations of alternative substrates. In addition to sulfate, Desulfoplanes can metabolize fumarate, formate, lactate, and acetate ${ }^{62}$.

According to OTU abundance, metabolic activities related to antimicrobial resistance were present in all samples, with a relative abundance lower than $2 \%$ (regarding the total metabolic activities; data not shown). Analyzing the gene ontologies belonging to the observed OTUs, some similarities and differences can be observed among the samples (Table 1).

Antimicrobial efflux mechanisms were present in the four samples and can include several types of efflux systems. The resistance-nodulation-division system (RND) operates as part of a tripartite system and is found ubiquitously in bacteria, archaea and eukaryotes. RND pump ontologies, such as AcrA/AcrB/TolC, MexAB/ OprM and AdeABC systems, were widely found in microorganisms from produced water samples. These systems can extrude multiple antimicrobials using energy conversion from the proton motive force due to their broad substrate specificity ${ }^{63-65}$. Vikram et al., 2015 described efflux systems as the main resistance mechanism used by Pseudomonas fluorescens biofilms against glutaraldehyde. A comparison of the response to biocides of glutaraldehyde- and PBS-exposed biofilms at the transcriptomic level revealed the induction of genes related to RND systems and ABC transporters ${ }^{66}$.

Mechanisms related to target modification identified in the microbiome of produced water samples are derived from penicillin-binding proteins (PBPs), which, in addition to their role in cell wall synthesis, precisely in peptidoglycan crosslinking, are membrane-associated macromolecules that play key roles in resistance 


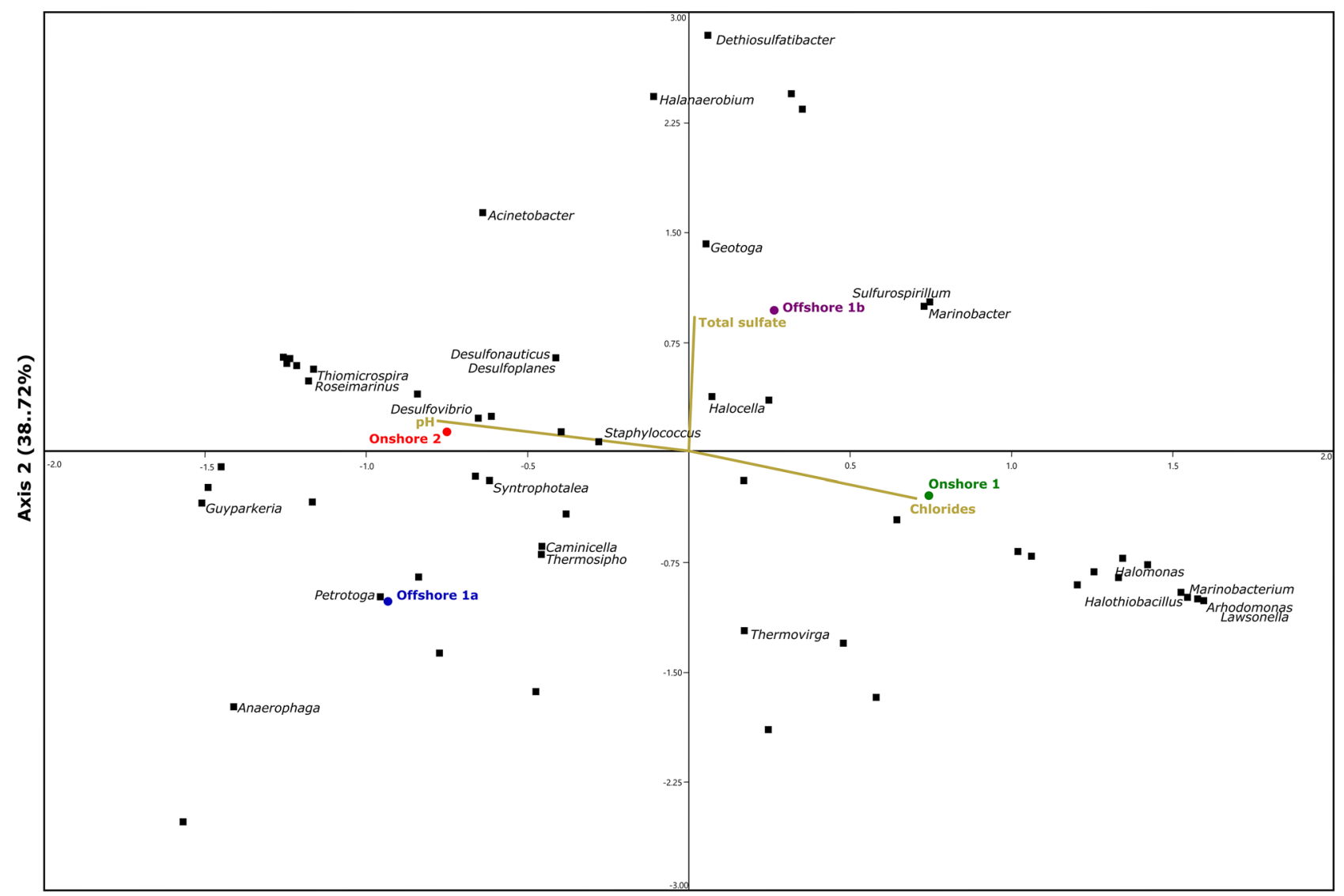

Axis $1(61.28 \%)$

Figure 4. Ordination tri plot of canonical correspondence analysis (CCA) between study sites and abiotic factors and genera.

mechanisms ${ }^{67}$. These enzymes are targets of $\beta$-lactam antibiotics, but conformational modifications can lead to the nonrecognition of the active site by antibiotics and, consequently, to antimicrobial resistance. PBP ontologies found in the samples indicated higher abundances of the genes $m r c A, m r d A$ and $f t s l$. Despite the cross-resistance between antibiotics and biocides being studied ${ }^{68}$, the role of PBP in resistance to biocides, specifically in oil fields, remains unclear.

The modification/degradation of antimicrobials by microorganisms can occur through the action of enzymes such as aldehyde dehydrogenase (ALDH), which catalyzes the oxidation of aldehydes, commonly present in biocides, to carboxylic acids. These enzymes are also involved in several other important metabolic processes, including glycerol production and ethanol oxidation ${ }^{69}$. ALDHs from different microorganisms show different substrate specificities but are able to degrade biocides such as glutaraldehyde and formaldehyde ${ }^{70,71}$. For these reasons, microorganisms able to produce ALDH enzymes should present advantages in terms of intrinsic resistance against aldehyde-based biocides.

Although present in lower abundance in most samples, $\beta$-lactamases, uniquely responsible for $\beta$-lactam degradation and resistance, were also present. Genes codifying $\beta$-lactamase classes A, B, C and D were found, but those codifying classes $\mathrm{C}$ and $\mathrm{D}$ demonstrated the highest abundances in the microbiomes.

In general, the microbiome from produced water samples demonstrated a huge variety of pathways involved in primary and secondary metabolism. Studies have shown that microorganisms found in oil fields carry out extremely complex "cross feeding" among them named anaerobic syntrophy ${ }^{57,72,73}$. Due to these microbial interactions and diverse microbiomes, oilfield microorganisms have an interdependent lifestyle, which must be deeply studied to fully understand their metabolic activities.

Biocidal resistance of SRB and APB consortia. SRB and APB consortia from produced water samples were previously enriched in specific media, except consortia from Offshore $1 \mathrm{~b}$ and Onshore 1, which did not present cultivable SRB or APB or cultivable SRB, respectively. MICs of biocides commonly applied in produced water treatment (50\% glutaraldehyde, 50\% THPS, 50\% DBNPA and 50\% ADBAC; active contents were equalized to facilitate the analysis) were applied to the SRB and APB consortia.

Table 2 shows the MIC results, where the different behaviors of the consortia against the biocides can be observed. The SRB consortia demonstrated higher susceptibility to glutaraldehyde and THPS, but at different levels. Offshore 1a presented a lower MIC during glutaraldehyde exposure $\left(<25 \mathrm{mg} \cdot \mathrm{L}^{-1}\right)$, while Onshore 2 presented reduced susceptibility to glutaraldehyde and THPS (MIC $=100 \mathrm{mg} \cdot \mathrm{L}^{-1}$, for both molecules). In general, 
A

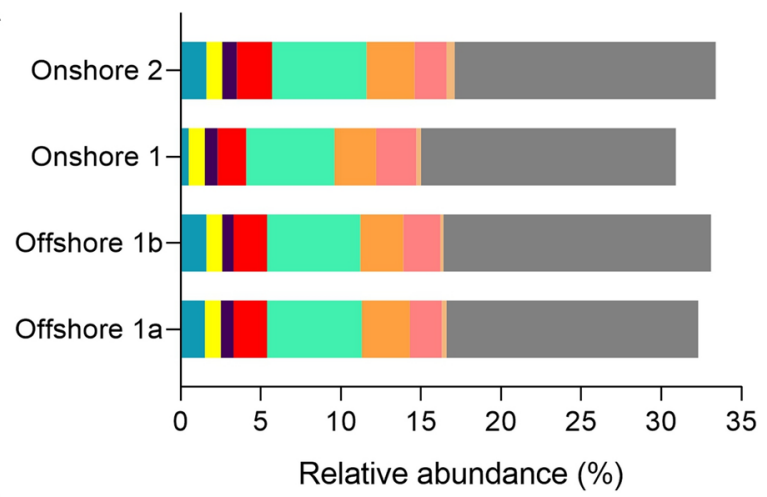

B

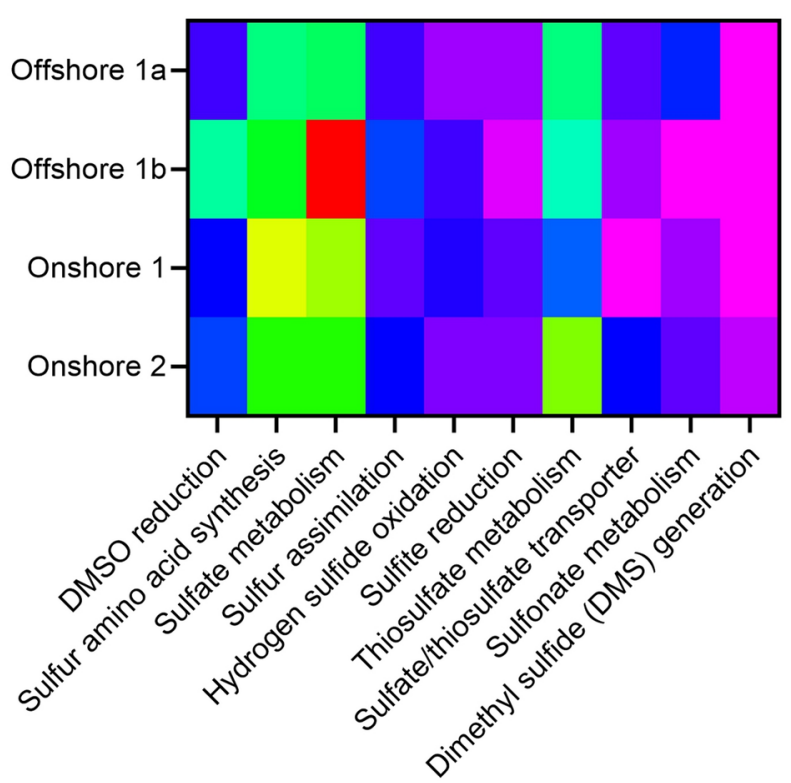

Biosynthesis of secondary metabolites

Degradation of aromatic compounds

- Biofilm formation

Quorum sensing

Carbon metabolism

Methane metabolism

Nitrogen metabolism

Sulfur metabolism

Antimicrobial resistance

Figure 5. Predictions using KEGG Database of functional abundance orthologous classes (A) and genes involved in sulfur metabolism (B).

SRB consortia were less susceptible to DBNPA and presented resistance against ADBAC. SRB resistance to ADBAC and other quaternary ammonium compounds has also been reported in several studies ${ }^{74-76}$ but needs further study.

High levels of APB resistance were reported, and unlike for SRB, only DBNPA and ADBAC showed effectiveness at the tested dosages. Glutaraldehyde and THPS required dosages above $500 \mathrm{mg} \mathrm{L}^{-1}$ to exert bacteriostatic effects on the APB consortia.

The use of alternative biocides can reduce microbial resistance, changing the biocidal mechanisms to control microorganisms. Green molecules are becoming a new trend due to their lower environmental impact and renewable sources. Natural oils such as lemon ${ }^{77}$, neem ${ }^{78}$, and clove oils ${ }^{79,80}$ and plant extracts such as those of green tea ${ }^{81}$ and garlic ${ }^{81}$, amino acids $s^{82}$ and biosurfactants ${ }^{83}$ have all been successfully evaluated against oilfield microorganisms and biofilms. Another way to broaden the effectiveness of water treatment is the use of synergistic molecules, especially those with different modes of action or cell targets.

\section{Conclusions}

This work revealed the high diversity of extremophiles in the produced water microbiome, even in the samples collected from the same platform. Despite the diversity, SRB, APB and sulfur-reducing bacterial groups were found with high abundance in the four samples. Functional characterization of gene ontologies predicted for the microbiomes demonstrated similar activities, mostly due to the similar nature of the samples. In terms of resistance, the SRB and APB consortia enriched from produced water samples demonstrated varied resistance levels to biocides commonly used in water treatment, indicating a specific taxonomic response to each biocide and reinforcing the idea of the necessity of combined treatments (with more than one molecule) or new molecules to 


\begin{tabular}{|c|c|c|c|c|c|}
\hline \multirow[b]{2}{*}{ Metabolic process } & \multirow[b]{2}{*}{ Predicted gene } & \multicolumn{4}{|c|}{ Relative abundance (\%) } \\
\hline & & \begin{tabular}{|l|} 
Offshore 1a \\
\end{tabular} & Offshore 1b & Onshore 1 & Onshore 2 \\
\hline \multirow{7}{*}{ Efflux mechanisms } & AcrA & 5.54 & 6.52 & 12.88 & 6.49 \\
\hline & $A c r B$ & 4.90 & 6.06 & 9.55 & 5.84 \\
\hline & TolC & 3.39 & 0.71 & 8.03 & 2.82 \\
\hline & AdeA & - & - & 0.02 & 0.01 \\
\hline & $A d e B$ & - & - & 0.02 & 0.01 \\
\hline & AdeC & - & - & 0.08 & 0.01 \\
\hline & OprM & - & - & 0.27 & 0.73 \\
\hline \multirow{3}{*}{ Target modification } & $m r c A$ & 7.20 & 8.81 & 12.48 & 7.67 \\
\hline & $m r d A$ & 7.07 & 8.85 & 11.44 & 7.58 \\
\hline & ftsl & 4.10 & 5.97 & 8.64 & 5.86 \\
\hline \multirow{5}{*}{ Modification/degradation of antimicrobial compounds } & $A L D H$ & 4.04 & 3.39 & - & 3.96 \\
\hline & ampC & - & - & 0.11 & 0.03 \\
\hline & ampG & 1.71 & 0.68 & 4.68 & 1.49 \\
\hline & penB & 1.39 & 0.01 & 1.02 & 0.76 \\
\hline & blaZ & - & - & 0.46 & - \\
\hline
\end{tabular}

Table 1. Prediction by KEGG Orthology of the relative abundance of antimicrobial resistance genes in produced water samples. ${ }^{a}$ Abundance relative to total antimicrobial resistance mechanisms.

\begin{tabular}{|c|c|c|c|c|c|c|}
\hline \multirow[b]{2}{*}{ Biocide } & \multicolumn{3}{|l|}{ SRB } & \multicolumn{3}{|l|}{ APB } \\
\hline & Dosage $\left(\mathbf{m g} \cdot \mathbf{L}^{-1}\right)$ & Offshore 1a & Onshore 2 & Offshore 1a & Onshore 1 & Onshore 2 \\
\hline Positive control & 0 & + & + & + & + & + \\
\hline \multirow{5}{*}{ Glutaraldehyde 50\% } & 25 & - & + & + & + & + \\
\hline & 50 & - & + & + & + & + \\
\hline & 100 & - & - & + & + & + \\
\hline & 250 & - & - & + & + & + \\
\hline & 500 & - & - & + & + & + \\
\hline \multirow{5}{*}{$\begin{array}{l}\text { THPS } \\
50 \%\end{array}$} & 25 & + & + & + & + & + \\
\hline & 50 & + & + & + & + & + \\
\hline & 100 & + & - & + & + & + \\
\hline & 250 & - & - & + & + & + \\
\hline & 500 & - & - & + & + & + \\
\hline \multirow{5}{*}{$\begin{array}{l}\text { DBNPA } \\
50 \%\end{array}$} & 25 & + & + & + & + & + \\
\hline & 50 & + & + & + & + & + \\
\hline & 100 & + & + & + & + & + \\
\hline & 250 & + & - & - & - & - \\
\hline & 500 & + & - & - & - & - \\
\hline \multirow{5}{*}{$\begin{array}{l}\text { ADBAC } \\
50 \%\end{array}$} & 25 & + & + & + & + & + \\
\hline & 50 & + & + & + & + & + \\
\hline & 100 & + & + & + & + & - \\
\hline & 250 & + & + & + & + & - \\
\hline & 500 & + & + & - & + & - \\
\hline
\end{tabular}

Table 2. MICs of glutaraldehyde, THPS, DBNPA and ADBAC against APB and SRB consortia from produced water samples in Modified Postgate E medium (for SRB) and Phenol Red Glucose Broth (for APB). +, positive growth; -, negative growth.

broaden treatment effectiveness. To confirm the findings found in this work, further evaluations to identify the bacterial composition of SRB and APB consortia need to be carried out in addition to further resistance studies.

Received: 6 May 2021; Accepted: 1 November 2021

Published online: 29 November 2021 


\section{References}

1. Kannan, P., Su, S. S., Mannan, M. S., Castaneda, H. \& Vaddiraju, S. A review of characterization and quantification tools for microbiologically influenced corrosion in the oil and gas industry: Current and future trends. Ind. Eng. Chem. Res. 57, 13895-13922 (2018).

2. Ismail, W. A., Van Hamme, J. D., Kilbane, J. J. \& Gu, J.-D. Editorial: Petroleum microbial biotechnology: Challenges and prospects. Front. Microbiol. 8, 833 (2017).

3. Kahrilas, G. A., Blotevogel, J., Stewart, P. S. \& Borch, T. Biocides in hydraulic fracturing fluids: A critical review of their usage, mobility, degradation, and toxicity. Environ. Sci. Technol. 49, 16-32 (2015).

4. Korenblum, E., Valoni, É., Penna, M. \& Seldin, L. Bacterial diversity in water injection systems of Brazilian offshore oil platforms. Appl. Microbiol. Biotechnol. 85, 791-800 (2010).

5. Li, X. X. et al. Microbiota and their affiliation with physiochemical characteristics of different subsurface petroleum reservoirs. Int. Biodeterior. Biodegradation https://doi.org/10.1016/j.ibiod.2017.02.005 (2017).

6. Rajbongshi, A. \& Gogoi, S. B. A review on anaerobic microorganisms isolated from oil reservoirs. World J. Microbiol. Biotechnol. 37, 1-19 (2021).

7. Chapman, J. S. Biocide resistance mechanisms. Int. Biodeterior. Biodegrad. https://doi.org/10.1016/S0964-8305(02)00097-5 (2003).

8. Caporaso, J. G. et al. Global patterns of $16 \mathrm{~S}$ rRNA diversity at a depth of millions of sequences per sample. Proc. Natl. Acad. Sci. 108, 4516-4522 (2011).

9. Schloss, P. D. et al. Introducing mothur: Open-source, platform-independent, community-supported software for describing and comparing microbial communities. Appl. Environ. Microbiol. 75, 7537-7541 (2009).

10. Yilmaz, P. et al. The SILVA and "all-species living tree project (LTP)" taxonomic frameworks. Nucleic Acids Res. 42, D643-D648 (2014).

11. Douglas, G. M. et al. PICRUSt2: An improved and extensible approach for metagenome inference. BioRxiv https://doi.org/10. $1101 / 672295$ (2019)

12. Kanehisa, M., Furumichi, M., Sato, Y., Ishiguro-Watanabe, M. \& Tanabe, M. KEGG: Integrating viruses and cellular organisms. Nucleic Acids Res. 49, D545-D551 (2021).

13. Kanehisa, M. Toward understanding the origin and evolution of cellular organisms. Protein Sci. 28, 1947-1951 (2019).

14. Kanehisa, M. \& Goto, S. KEGG: Kyoto encyclopedia of genes and genomes. Nucleic Acids Res. 28, 27-30 (2000).

15. Kanehisa, M., Sato, Y., Kawashima, M., Furumichi, M. \& Tanabe, M. KEGG as a reference resource for gene and protein annotation. Nucleic Acids Res. https://doi.org/10.1093/nar/gkv1070 (2016).

16. Balch, W. E. \& Wolfe, R. S. New approach to the cultivation of methanogenic bacteria: 2-mercaptoethanesulfonic acid (HS-CoM)dependent growth of Methanobacterium ruminantium in a pressureized atmosphere. Appl. Environ. Microbiol. 32, 781-791 (1976).

17. Postgate, J. R. The Sulphate-Reducing Bacteria (Cambridge University Press, 1984).

18. Jain, D. K. Evaluation of the semisolid Postgate's B medium for enumerating sulfate-reducing bacteria. J. Microbiol. Methods 22, 27-38 (1995).

19. Schug, A. R. et al. Biocide susceptibility testing of bacteria: Development of a broth microdilution method. Vet. Microbiol. 248, 108791 (2020).

20. Agência Nacional do Petróleo, G. N. e B. (ANP). Boletim da Produção de Petróleo e Gás Natural. (2020).

21. Al-Ghouti, M. A., Al-Kaabi, M. A., Ashfaq, M. Y. \& Dana, D. A. Produced water characteristics, treatment and reuse: A review. J. Water Process Eng. https://doi.org/10.1016/j.jwpe.2019.02.001 (2019).

22. Dickhout, J. M. et al. Produced water treatment by membranes: A review from a colloidal perspective. J. Colloid Interface Sci. https://doi.org/10.1016/j.jcis.2016.10.013 (2017).

23. Xu, D., Li, Y. \& Gu, T. Mechanistic modeling of biocorrosion caused by biofilms of sulfate reducing bacteria and acid producing bacteria. Bioelectrochemistry https://doi.org/10.1016/j.bioelechem.2016.03.003 (2016).

24. Marciales, A., Peralta, Y., Haile, T., Crosby, T. \& Wolodko, J. Mechanistic microbiologically influenced corrosion modeling-A review. Corros. Sci. https://doi.org/10.1016/j.corsci.2018.10.004 (2019).

25. Jurelevicius, D. et al. Long-term souring treatment using nitrate and biocides in high-temperature oil reservoirs. Fuel 288, 119731 (2021).

26. Roychoudhury, A. N., Cowan, D., Porter, D. \& Valverde, A. Dissimilatory sulphate reduction in hypersaline coastal pans: An integrated microbiological and geochemical study. Geobiology 11, 224-233 (2013).

27. Muyzer, G. \& Stams, A. J. M. The ecology and biotechnology of sulphate-reducing bacteria. Nat. Rev. Microbiol. https://doi.org/ $10.1038 /$ nrmicro1892 (2008).

28. Qian, Z., Tianwei, H., Mackey, H. R., van Loosdrecht, M. C. M. \& Guanghao, C. Recent advances in dissimilatory sulfate reduction: From metabolic study to application. Water Res. https://doi.org/10.1016/j.watres.2018.11.018 (2019).

29. Govil, T., Rathinam, N. K., Salem, D. R. \& Sani, R. K. Chapter 35-Taxonomical diversity of extremophiles in the deep biosphere. in (eds. Das, S. \& Dash, H. R. B. T.-M. D. in the G. E.) 631-656 (Academic Press, 2019). https://doi.org/10.1016/B978-0-12-814849-5. 00035-6.

30. Fauque, G. D. \& Barton, L. L. Chapter 1-Hemoproteins in dissimilatory sulfate- and sulfur-reducing prokaryotes. in (ed. Poole, R. K. B. T.-A. in M. P.) vol. 60 1-90 (Academic Press, 2012).

31. Guy Riefler, R., Krohn, J., Stuart, B. \& Socotch, C. Role of sulfur-reducing bacteria in a wetland system treating acid mine drainage. Sci. Total Environ. https://doi.org/10.1016/j.scitotenv.2008.01.024 (2008).

32. Sun, J. et al. Arsenite removal without thioarsenite formation in a sulfidogenic system driven by sulfur reducing bacteria under acidic conditions. Water Res. https://doi.org/10.1016/j.watres.2018.12.027 (2019).

33. Wang, J. T., Zhang, L., Kang, Y., Chen, G. \& Jiang, F. Long-term feeding of elemental sulfur alters microbial community structure and eliminates mercury methylation potential in sulfate-reducing bacteria abundant activated sludge. Environ. Sci. Technol. https:// doi.org/10.1021/acs.est.7b06399 (2018).

34. Guo, J., Wang, J., Qiu, Y., Sun, J. \& Jiang, F. Realizing a high-rate sulfidogenic reactor driven by sulfur-reducing bacteria with organic substrate dosage minimization and cost-effectiveness maximization. Chemosphere https://doi.org/10.1016/j.chemosphere.2019. 124381 (2019).

35. Wang, Y. et al. Corrosion of EH40 steel affected by Halomonas titanicae dependent on electron acceptors utilized. Corros. Sci. 182, 109263 (2021).

36. Procópio, L. The oil spill and the use of chemical surfactant reduce microbial corrosion on API 5L steel buried in saline soil. Environ. Sci. Pollut. Res. 28, 26975-26989 (2021).

37. An, B. A., Kunte, H.-J. \& Koerdt, A. Microbiologically influenced corrosion by halophilic (salt-loving) nitrate and sulfate-reducing microorganisms. (2021)

38. Elumalai, P. et al. Characterization of crude oil degrading bacterial communities and their impact on biofilm formation. Environ. Pollut. 286, 117556 (2021).

39. Oren, A. The order halanaerobiales, and the families halanaerobiaceae and halobacteroidaceae. in The Prokaryotes: Firmicutes and Tenericutes (eds. Rosenberg, E., DeLong, E. F., Lory, S., Stackebrandt, E. \& Thompson, F.) 153-177 (Springer Berlin Heidelberg, 2014). https://doi.org/10.1007/978-3-642-30120-9_218. 
40. Liang, R., Grizzle, R., Duncan, K., McInerney, M. \& Suflita, J. Roles of thermophilic thiosulfate-reducing bacteria and methanogenic archaea in the biocorrosion of oil pipelines. Front. Microbiol. 5, 89 (2014).

41. Mata, J. A., Martínez-Cánovas, J., Quesada, E. \& Béjar, V. A detailed phenotypic characterisation of the type strains of halomonas species. Syst. Appl. Microbiol. 25, 360-375 (2002).

42. Wang, D., Ramadan, M., Kumseranee, S., Punpruk, S. \& Gu, T. Mitigating microbiologically influenced corrosion of an oilfield biofilm consortium on carbon steel in enriched hydrotest fluid using 2,2-dibromo-3-nitrilopropionamide (DBNPA) enhanced by a 14-mer peptide. J. Mater. Sci. Technol. 57, 146-152 (2020).

43. Grouzdev, D. S. et al. Draft genome sequence of geotoga petraea strain HO-Geo 1, isolated from a petroleum reservoir in Russia. Microbiol. Resour. Announc. 8, e00706-e719 (2021).

44. Soler, A. J. et al. Identification and characterization of planktonic and sessile consortium associated with microbiologically influenced corrosion (MIC) in the oil and gas industry. In CORROSION 2021 (OnePetro, 2021).

45. González-Benítez, N. et al. Bacterial diversity in aqueous/sludge phases within diesel fuel storage tanks. World J. Microbiol. Biotechnol. 36, 180 (2020).

46. Vigneron, A. et al. Succession in the petroleum reservoir microbiome through an oil field production lifecycle. ISME J. https:// doi.org/10.1038/ismej.2017.78 (2017).

47. Waite, D. W. et al. Proposal to reclassify the proteobacterial classes deltaproteobacteria and oligoflexia, and the phylum thermodesulfobacteria into four phyla reflecting major functional capabilities. Int. J. Syst. Evol. Microbiol. https://doi.org/10.1099/ijsem.0. $004213(2020)$.

48. Gray, N. D. et al. The quantitative significance of Syntrophaceae and syntrophic partnerships in methanogenic degradation of crude oil alkanes. Environ. Microbiol. https://doi.org/10.1111/j.1462-2920.2011.02570.x (2011).

49. Vigneron, A., Cruaud, P., Ducellier, F., Head, I. M. \& Tsesmetzis, N. Syntrophic hydrocarbon degradation in a decommissioned off-shore subsea oil storage structure. Microorganisms 9 (2021).

50. Singh, B. P., Rateb, M. E., Rodriguez-Couto, S., Polizeli, M. L. T. M. \& Li, W.-J. Editorial: Microbial secondary metabolites: Recent developments and technological challenges. Front. Microbiol. 10, 914 (2019).

51. Yang, Z. et al. Biostimulation of sulfate-reducing bacteria used for treatment of hydrometallurgical waste by secondary metabolites of urea decomposition by Ochrobactrum sp. POC9: From genome to microbiome analysis. Chemosphere 282, 131064 (2021).

52. Sivakumar, K. et al. Salinity-mediated increment in sulfate reduction, biofilm formation, and quorum sensing: A potential connection between quorum sensing and sulfate reduction?. Front. Microbiol. 10, 188 (2019).

53. Parsek, M. R. \& Greenberg, E. P. Sociomicrobiology: The connections between quorum sensing and biofilms. Trends Microbiol. 13, 27-33 (2005).

54. Mah, T. F. C. \& O'Toole, G. A. Mechanisms of biofilm resistance to antimicrobial agents. Trends Microbiol. https://doi.org/10.1016/ S0966-842X(00)01913-2 (2001).

55. Vikram, A., Lipus, D. \& Bibby, K. Metatranscriptome analysis of active microbial communities in produced water samples from the Marcellus Shale. Microb. Ecol. https://doi.org/10.1007/s00248-016-0811-z (2016).

56. Johnson, R. J., Folwell, B. D., Wirekoh, A., Frenzel, M. \& Skovhus, T. L. Reservoir souring-Latest developments for application and mitigation. J. Biotechnol. https://doi.org/10.1016/j.jbiotec.2017.04.003 (2017).

57. Rabus, R. et al. Anaerobic microbial degradation of hydrocarbons: From enzymatic reactions to the environment. J. Mol. Microbiol. Biotechnol. https://doi.org/10.1159/000443997 (2016).

58. Prajapat, G., Rellegadla, S., Jain, S. \& Agrawal, A. Application of biotechnology in oil and gas industries. In Environmental Microbiology and Biotechnology 113-133 (Springer, 2021).

59. Piceno, Y. M. et al. Temperature and injection water source influence microbial community structure in four Alaskan North Slope hydrocarbon reservoirs. Front. Microbiol. https://doi.org/10.3389/fmicb.2014.00409 (2014).

60. Miralles-Robledillo, J. M., Torregrosa-Crespo, J., Martínez-Espinosa, R. M. \& Pire, C. DMSO reductase family: Phylogenetics and applications of extremophiles. Int. J. Mol. Sci. 20 (2019).

61. Thume, K. et al. The metabolite dimethylsulfoxonium propionate extends the marine organosulfur cycle. Nature 563, 412-415 (2018).

62. Watanabe, M., Kojima, H. \& Fukui, M. Desulfoplanes formicivorans gen. nov., sp. nov., a novel sulfate-reducing bacterium isolated from a blackish meromictic lake, and emended description of the family Desulfomicrobiaceae. Int. J. Syst. Evol. Microbiol. 65, 1902-1907 (2015).

63. Pos, K. M. Drug transport mechanism of the AcrB efflux pump. Biochim. Biophys. Acta Proteins Proteomics https://doi.org/10. 1016/j.bbapap.2008.12.015 (2009).

64. Yoon, E. J. et al. Contribution of the ade resistance-nodulation-cell division-type efflux pumps to fitness and pathogenesis of Acinetobacter baumannii. MBio https://doi.org/10.1128/mBio.00697-16 (2016).

65. Auda, I. G., Ali Salman, I. M. \& Odah, J. G. Efflux pumps of Gram-negative bacteria in brief. Gene Rep. 20, 100666 (2020).

66. Vikram, A., Bomberger, J. M. \& Bibby, K. J. Efflux as a glutaraldehyde resistance mechanism in Pseudomonas fluorescens and Pseudomonas aeruginosa biofilms. Antimicrob. Agents Chemother. https://doi.org/10.1128/AAC.05152-14 (2015).

67. Macheboeuf, P., Contreras-Martel, C., Job, V., Dideberg, O. \& Dessen, A. Penicillin binding proteins: Key players in bacterial cell cycle and drug resistance processes. FEMS Microbiol. Rev. https://doi.org/10.1111/j.1574-6976.2006.00024.x (2006).

68. Cândido, E. S., de Barros, E., Cardoso, M. H. \& Franco, O. L. Bacterial cross-resistance to anti-infective compounds. Is it a real problem?. Curr. Opin. Pharmacol. https://doi.org/10.1016/j.coph.2019.05.004 (2019).

69. Singh, S. et al. Aldehyde dehydrogenases in cellular responses to oxidative/ electrophilicstress. Free Radical Biol. Med. https://doi. org/10.1016/j.freeradbiomed.2012.11.010 (2013)

70. Gómez-Manzo, S. et al. The aldehyde dehydrogenase (ALDH) of Gluconacetobacter diazotrophicus is a Quinohemeprotein containing PQQ, cytochrome b and cytochrome c. molecular and catalytic properties. J. Bacteriol. https://doi.org/10.1128/JB.00589-10 (2010).

71. Jaureguibeitia, A., Saá, L., Llama, M. J. \& Serra, J. L. Purification, characterization and cloning of aldehyde dehydrogenase from Rhodococcus erythropolis UPV-1. Appl. Microbiol. Biotechnol. https://doi.org/10.1007/s00253-006-0558-4 (2007).

72. McInerney, M. J., Sieber, J. R. \& Gunsalus, R. P. Syntrophy in anaerobic global carbon cycles. Curr. Opin. Biotechnol. https://doi. org/10.1016/j.copbio.2009.10.001 (2009).

73. Elumalai, P. et al. Role of thermophilic bacteria (Bacillus and Geobacillus) on crude oil degradation and biocorrosion in oil reservoir environment. 3 Biotech 9, 79 (2019).

74. Xue, Y. \& Voordouw, G. Control of microbial sulfide production with biocides and nitrate in oil reservoir simulating bioreactors. Front. Microbiol. https://doi.org/10.3389/fmicb.2015.01387 (2015).

75. Lee, M. H. P., Caffrey, S. M., Voordouw, J. K. \& Voordouw, G. Effects of biocides on gene expression in the sulfate-reducing bacterium Desulfovibrio vulgaris Hildenborough. Appl. Microbiol. Biotechnol. https://doi.org/10.1007/s00253-010-2596-1 (2010).

76. Senthilmurugan, B. et al. Microbially induced corrosion in oilfield: Microbial quantification and optimization of biocide application. J. Chem. Technol. Biotechnol. https://doi.org/10.1002/jctb.6073 (2019).

77. Souza, P. M. et al. Growth inhibition of sulfate-reducing bacteria in produced water from the petroleum industry using essential oils. Molecules 22 (2017).

78. Parthipan, P. et al. Neem extract as a green inhibitor for microbiologically influenced corrosion of carbon steel API 5LX in a hypersaline environments. J. Mol. Liq. 240, 121-127 (2017). 
79. Purwasena, I. A., Astuti, D. I., Taufik, I. \& Putri, F. Z. The potential of clove essential oil microemulsion as an alternative biocide against Pseudomonas aeruginosa biofilm. J. Pure Appl. Microbiol 14, 261-269 (2020).

80. Parthipan, P., AlSalhi, M. S., Devanesan, S. \& Rajasekar, A. Evaluation of Syzygium aromaticum aqueous extract as an eco-friendly inhibitor for microbiologically influenced corrosion of carbon steel in oil reservoir environment. Bioprocess. Biosyst. Eng. 44, 1441-1452 (2021).

81. Md Zain, W. S., Hairul Salleh, N. I. \& Abdullah, A. Natural biocides for mitigation of sulphate reducing bacteria. Int. J. Corros. 2018, 3567569 (2018).

82. Li, Y., Jia, R., Al-Mahamedh, H. H., Xu, D. \& Gu, T. Enhanced biocide mitigation of field biofilm consortia by a mixture of D-amino acids. Front. Microbiol. 7, 896 (2016).

83. Parthipan, P., Sabarinathan, D., Angaiah, S. \& Rajasekar, A. Glycolipid biosurfactant as an eco-friendly microbial inhibitor for the corrosion of carbon steel in vulnerable corrosive bacterial strains. J. Mol. Liq. 261, 473-479 (2018).

\section{Author contributions}

G.P. conducted the experiments, wrote the main manuscript text, and prepared Fig. 5 and Tables 1 and 2. H. P. conducted the taxonomic analysis and prepared Figs. 1, 2, 3, 4 and 5. G.C. was responsible for the financial support of the project, supervised the experiments and wrote the manuscript. All the authors reviewed the manuscript.

\section{Funding}

The fund was provided by Coordenação de Aperfeiçoamento de Pessoal de Nível Superior (Financial code 001).

\section{Competing interests}

The authors declare no competing interests.

\section{Additional information}

Supplementary Information The online version contains supplementary material available at https://doi.org/ 10.1038/s41598-021-02494-7.

Correspondence and requests for materials should be addressed to G.C.

Reprints and permissions information is available at www.nature.com/reprints.

Publisher's note Springer Nature remains neutral with regard to jurisdictional claims in published maps and institutional affiliations.

(c) Open Access This article is licensed under a Creative Commons Attribution 4.0 International License, which permits use, sharing, adaptation, distribution and reproduction in any medium or format, as long as you give appropriate credit to the original author(s) and the source, provide a link to the Creative Commons licence, and indicate if changes were made. The images or other third party material in this article are included in the article's Creative Commons licence, unless indicated otherwise in a credit line to the material. If material is not included in the article's Creative Commons licence and your intended use is not permitted by statutory regulation or exceeds the permitted use, you will need to obtain permission directly from the copyright holder. To view a copy of this licence, visit http://creativecommons.org/licenses/by/4.0/.

(c) The Author(s) 2021 